\title{
Characterization of Proton-Bound Acetate Dimers in Ion Mobility Spectrometry
}

\author{
Christian Schack Pedersen, ${ }^{a}$ Frants Roager Lauritsen, ${ }^{a}$ Alexey Sysoev, \\ Anna-Kaisa Viitanen, ${ }^{c}$ Jyrki M. Mäkelä, ${ }^{c}$ Alexey Adamov, ${ }^{\mathrm{d}, \mathrm{e}}$ \\ Jaakko Laakia, ${ }^{\mathrm{d}}$ Timo Mauriala, ${ }^{\mathrm{d}, \mathrm{e}}$ and Tapio Kotiaho ${ }^{\mathrm{d}, \mathrm{e}}$ \\ ${ }^{a}$ Department of Chemistry, University of Copenhagen, Copenhagen, Denmark \\ b Moscow Engineering Physics Institute (State University), Moscow, Russia \\ cAerosol Physics Laboratory, Tampere University of Technology, Tampere, Finland \\ ${ }^{d}$ Laboratory of Analytical Chemistry, Department of Chemistry, University of Helsinki, Helsinki, Finland \\ e Division of Pharmaceutical Chemistry, Faculty of Pharmacy, University of Helsinki, Helsinki, Finland
}

Ionized acetates were used as model compounds to describe gas-phase behavior of oxygen containing compounds with respect to their formation of dimers in ion mobility spectrometry (IMS). The ions were created using corona discharge at atmospheric pressure and separated in a drift tube before analysis of the ions by mass spectrometry. At the ambient operational temperature and pressure used in our instrument, all acetates studied formed dimers. Using a homolog series of $n$-alkyl-acetates, we found that the collision cross section of a dimer was smaller than that of a monomer with the same reduced mass. Our experiments also showed that the reduced mobility of acetate dimers with different functional groups increased in the order $n$-alkyl $\leq$ branched chain alkyl $\leq$ cyclo alkyl $<$ aromat. For mixed $n$-alkyl dimers we found that the reduced mobility of acetate dimers having the same number of carbons, for example a dimer of acetyl acetate and hexyl acetate has the same reduced mobility as a dimer composed of two butyl acetates. The fundamental behavior of acetate monomers and dimers described in this paper will assist in a better understanding of the influence of dimer formation in ion mobility spectrometry. (J Am Soc Mass Spectrom 2008, 19, 1361-1366) (C) 2008 American Society for Mass Spectrometry

I on mobility spectrometry (IMS) is a versatile technique that has found widespread application in many areas, such as military and civil security applications, where it has been used to detect chemical warfare agents, explosives, and drugs [1-4]. The major advantages of IMS instruments are their small size, low power consumption, and capability to operate at atmospheric pressure, which makes them highly suited for real time analysis in the field [1,5]. However, IMS spectra are sensitive toward changes in analytical conditions such as humidity, pressure, temperature, and matrix [6]. This feature makes it difficult to use the instrument for analysis of more than a limited number of prespecified compounds at a time, and reagent gases are often used to simplify the spectra either by suppressing certain ions $[7,8]$ or by selective dimer formation [9].

The creation of an IMS spectrum involves gas-phase ionization followed by a separation of the ions based on their mobility in an electrical field at pressures between $\sim 10^{2}$ and $10^{5} \mathrm{~Pa}$. As a result of the ionization at atmospheric or near atmospheric pressure the ionized sample molecules may undergo several different trans-

Address reprint requests to Mr. C. S. Pedersen, Department of Chemistry, University of Copenhagen, Universitetsparken 5, DK-2100 Copenhagen, Denmark. E-mail: csp@kemi.ku.dk formations such as fragmentation, rearrangement, and cluster formation. In particular molecules containing functional oxygen or nitrogen, atoms tend to make clusters with water molecules or other molecules with similar hydrogen bonding capabilities. Since the separation of ions in an IMS experiment depends upon both charge and size, cluster formation has a large influence upon the observed spectra and mobilities. The formation of clusters can be advantageous. For example, a problem with interfering background chemicals can be solved by adding a reagent gas that selectively creates a dimer with the analyte of interest [9].

The present investigation focuses upon the characteristics of ionized acetates. Acetates are ionized at the carbonyl oxygen [10,11], and at elevated analyte concentration they form proton bound dimers [10]. Dimers are formed between the acetates and most other molecules with oxygen or amine functionalities [12], and they are stable even at elevated temperatures [13]. The acetates are useful model compounds because they have similar characteristics as many compound classes such as alcohols, amines, aldehydes, ketones, acids, amides, and organophosphorus compounds with respect to gas-phase behavior, e.g., formation of clusters, response to humidity, temperature, and concentration. These compound classes are interesting in a multitude of analytical applications, and the behavior of their 
dimers is important both from a fundamental and a practical point of view.

\section{Experimental}

\section{Chemicals}

To elucidate the fundamental behavior of acetates with respect to the mobility of their monomers and proton bound dimers in IMS experiments, we investigated a large number of different acetates. The chemical structure of the acetates used is shown in Figure 1, together with a nomenclature of abbreviations used. Four different alkyl substituents (R) were used: $n$-alkyl substituents with the number of carbons ranging from 1 to 8 $\left(\mathrm{nC}_{\mathrm{X}}\right)$, 2-ethyl-butyl $\left(\mathrm{iC}_{6}\right)$, cyclo-hexyl $\left(\mathrm{cC}_{6}\right)$, and benzyl $\left(\mathrm{pC}_{6}\right)$. All experiments involving dimers were performed using homolog series of dimers, where one of the acetates (the acetate of investigation) was kept constant, whereas the other acetate in the dimer was an $n$-alkyl acetate of varying length. The dimer series were: $n$-alkyl $n$-alkyl acetate dimers $\left(\mathrm{nC}_{\mathrm{X}^{*}} \mathrm{nC}_{\mathrm{X}^{\prime}}\right)$, 2-ethyl-butyl (iso-hexyl) $n$-alkyl acetate dimers $\left(\mathrm{iC}_{6}{ }^{*} \mathrm{nC}_{\mathrm{X}}\right)$, cyclohexyl ${ }^{*} n$ alkyl acetate dimers $\left(\mathrm{cC}_{6^{*}} \mathrm{nC}_{\mathrm{X}}\right)$, and phenyl ${ }^{*} n$-hexyl acetate

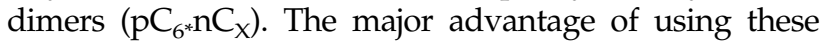
series of dimers is that it makes it possible to compare dimers with different types of substituents over a broad range of masses.

\section{Experimental Strategy}

The samples were prepared as individual compounds or mixtures of three or four acetates dissolved in pentane and injected by a syringe pump into a gas calibrator (Environics OY, Mikkeli, Finland), where it was mixed with pure nitrogen. The gas-phase concentration was optimized with respect to peak width and signal to noise ratio for each mixture, and was between $60 \mathrm{ppb}$ and $140 \mathrm{ppb}$. The drift time and intensities of the monomers and dimers were recorded using a traditional drift tube with mass spectrometric detection (detailed description below). The identity of the emerging monomers and dimers were verified by mass spectrometric detection of the protonated molecular ions. In the case of dimers, the dimer could be dissociated into its two constituents by collisional activation in the

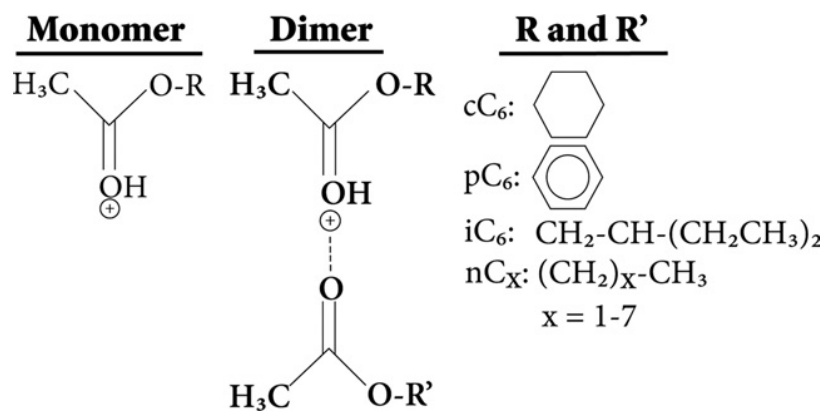

Figure 1. Structure of the ions investigated in this study.
IMS-MS interface for mass spectrometric identification of the individual acetates in the dimer.

To minimize the influence of external factors such as temperature, pressure, and electrical field an internal standard [2,6-di-tert-butyl pyridine (2,6-DtBP)] [14, 15] was typically added to the sample mixtures and reduced mobilities of acetates and 2,6-DtBP were normalized to give a reduced mobility of 2,6-DtBP of 1.42 $\mathrm{cm}^{2} /(\mathrm{V} \cdot \mathrm{s})$ [14] according to eq 1 :

$$
K_{0}^{C}=\frac{K_{0}^{I S}}{K_{M}^{I S}} \cdot K_{M}^{C}
$$

Where $K_{0}^{C}$ is the normalized reduced mobility of the compound, $K_{0}^{I S}$ is the literature reduced mobility of the internal standard (2,6-D $t \mathrm{BP}), K_{M}^{I S}$ the measured mobility of the internal standard, and $K_{M}^{C}$ the measured mobility of the compound.

The cluster formation process is humidity and temperature-dependent, and this effect can not be corrected for using the 2,6-DtBP internal standard, since 2,6-DtBP does not form clusters [16]. To reduce uncertainties in the cluster formation process caused by variations in temperature and humidity, we have made efforts to keep these parameters constant (see general conditions below).

\section{Instrument Description}

A custom made drift tube ion mobility spectrometer coupled to a triple quadrupole mass spectrometer (described in detail elsewhere [17]) was used in our experiments. The instrument consists of an ion source, a drift tube, and a mass spectrometer. The ion source was a corona discharge ion source using point-to-plane geometry. This was chosen because the ionization chemistry of a corona discharge ion source is similar to the chemistry of a radioactive ion source, but with a higher ion density [18]. The ion source is connected to the drift tube by an orifice plate with a $3 \mathrm{~mm}$ hole. The drift tube consists of three regions, a desolvation region, a drift region, and an extraction region. The desolvation region serves to dry the ions when nebulization ion sources are used, and was of less importance in this study using gas-phase samples. The drift region is $13.3 \mathrm{~cm}$ long and each end is fitted with a Bradbury-Nielsen gate [19]. The extraction region serves to guide the ions through a pinhole and into the mass spectrometer.

The instrument was a triple quadrupole mass spectrometer API300 (Applied Biosystems-SCIEX, Concord, Ontario, Canada). Quadrupole mass spectrometers are generally not fast enough to permit a time resolution in the order of a millisecond, which is needed to resolve the peaks in IMS experiments. To circumvent this problem, a special operational procedure of the IMS instrument was used. The first gate of the IMS was opened for $300 \mu \mathrm{s}$ and after a delay corresponding to the drift time, the second gate was opened for $300 \mu \mathrm{s}$. By successively repeating the analysis with increasing 


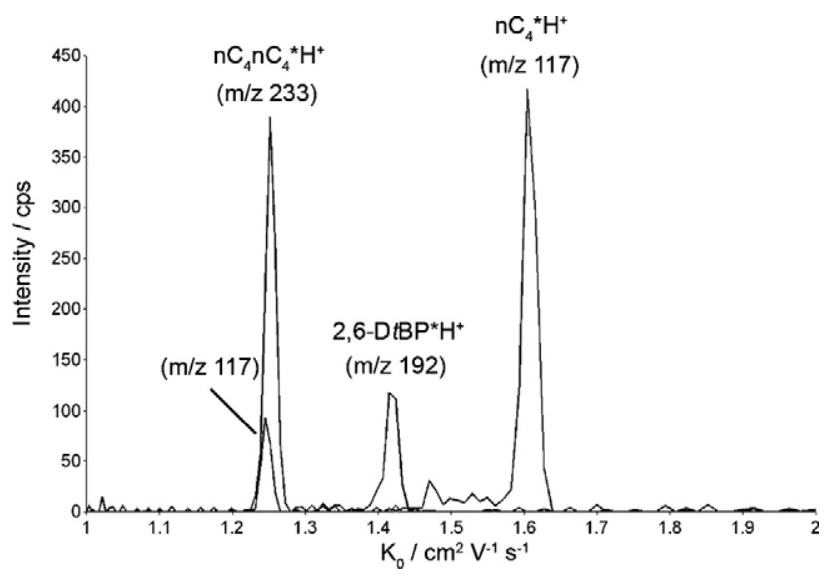

Figure 2. Ion mobility spectrum of butyl acetate and 2,6-DtBP. Number in brackets denotes the monitored mass.

delay between the opening of the two gates (in steps of $200 \mu \mathrm{s})$, an IMS spectrum with a time resolution better than $1 \mathrm{~ms}$ could be recorded. To increase the signal intensity, the mass spectrometer was operated in single ion monitoring mode (SIM), where only the masses of the protonated ions were monitored.

\section{General Conditions}

All chemicals were from Sigma-Aldrich (Steinheim, Germany) and used as received. The measurements were taken at ambient pressure and temperature in a thermostatic room. The nitrogen $(99.5 \%$, humidity 14 ppm, dewpoint $-57^{\circ} \mathrm{C}$ ) used as drift gas and for dilution was produced from pressurized air using a NGLCMS20 nitrogen generator (Labgas Instrument Co., Espoo, Finland). The flow of drift gas was 1.5 $\mathrm{L} / \mathrm{min}$ and the flow of sample was $0.7 \mathrm{~L} / \mathrm{min}$. To keep the humidity constant during the experiments the drift gas was passed through a series of driers and the humidity was measured with a dewpoint sensor (Vaisala DMT242; Helsinki, Finland).

\section{Results and Discussion}

Figure 2 shows a typical example of an IMS spectrum recorded of an acetate (butyl acetate). The protonated monomer was recorded at $\mathrm{m} / \mathrm{z} 117$, the proton bound dimer at $m / z$ 233, and the internal standard 2,6-DtBP at $\mathrm{m} / \mathrm{z} 192$ with normalized reduced mobilities of $1.60 \mathrm{~cm}^{2}$ $\mathrm{V}^{-1} \mathrm{~s}^{-1}, 1.25 \mathrm{~cm}^{2} \mathrm{~V}^{-1} \mathrm{~s}^{-1}$, and $1.42 \mathrm{~cm}^{2} \mathrm{~V}^{-1} \mathrm{~s}^{-1}$, respectively. A signal from $\mathrm{m} / \mathrm{z} 117$ is observed both at the protonated monomer and at the proton bound dimer showing that some of the proton bound dimers fragment in the IMS-MS interface. We do not observe any or only very little fragmentation of the dimers through the drift tube. This is in agreement with previous investigators [20], who found that the fragmentation of butyl acetate in the drift tube occurred when

Table 1. The measured reduced mobilities, normalized to $2,6-\mathrm{D} t \mathrm{BP}\left(\mathrm{K}_{0}=1.42\right)$

\begin{tabular}{|c|c|c|c|c|}
\hline Group & Abbreviation & Formula & Mass/u & $\mathrm{K}_{0} / \mathrm{cm}^{2} \mathrm{~V}^{-1} \mathrm{~S}^{-1}$ \\
\hline \multirow[t]{4}{*}{$\mathrm{nC}_{\mathrm{x}} n$-alkyl monomers } & $\mathrm{nC}_{2}$ & $\mathrm{C}_{4} \mathrm{H}_{8} \mathrm{O}_{2}{ }^{*} \mathrm{H}^{+}$ & 89 & 1.81 \\
\hline & $\mathrm{nC}_{4}$ & $\mathrm{C}_{6} \mathrm{H}_{12} \mathrm{O}_{2} * \mathrm{H}^{+}$ & 117 & 1.61 \\
\hline & $\mathrm{nC}_{6}$ & $\mathrm{C}_{8} \mathrm{H}_{16} \mathrm{O}_{2} * \mathrm{H}^{+}$ & 145 & 1.43 \\
\hline & $\mathrm{nC}_{8}$ & $\mathrm{C}_{8} \mathrm{H}_{20} \mathrm{O}_{2} * \mathrm{H}^{+}$ & 177 & 1.23 \\
\hline \multirow[t]{10}{*}{$\mathrm{nC}_{\mathrm{X}} \mathrm{nC}_{\mathrm{x}} n$-alkyl ${ }^{*} n$-alkyl dimers } & $\mathrm{nC}_{2} \mathrm{nC}_{2}$ & $\mathrm{C}_{8} \mathrm{H}_{16} \mathrm{O}_{4}{ }^{*} \mathrm{H}^{+}$ & 177 & 1.49 \\
\hline & $\mathrm{nC}_{2} \mathrm{nC}_{4}$ & $\mathrm{C}_{10} \mathrm{H}_{20} \mathrm{O}_{4} * \mathrm{H}^{+}$ & 205 & 1.36 \\
\hline & $\mathrm{nC}_{4} \mathrm{nC}_{4}$ & $\mathrm{C}_{12} \mathrm{H}_{24} \mathrm{O}_{4}{ }^{*} \mathrm{H}^{+}$ & 233 & 1.24 \\
\hline & $\mathrm{nC}_{3} \mathrm{nC}_{6}$ & $\mathrm{C}_{13} \mathrm{H}_{26} \mathrm{O}_{4}{ }^{*} \mathrm{H}^{+}$ & 247 & 1.18 \\
\hline & $\mathrm{nC}_{4} \mathrm{nC}_{6}$ & $\mathrm{C}_{14} \mathrm{H}_{28} \mathrm{O}_{4}{ }^{*} \mathrm{H}^{+}$ & 261 & 1.15 \\
\hline & $\mathrm{nC}_{3} \mathrm{nC}_{8}$ & $\mathrm{C}_{15} \mathrm{H}_{30} \mathrm{O}_{4}{ }^{*} \mathrm{H}^{+}$ & 275 & 1.12 \\
\hline & $\mathrm{nC}_{6} \mathrm{nC}_{6}$ & $\mathrm{C}_{16} \mathrm{H}_{32} \mathrm{O}_{4}{ }^{*} \mathrm{H}^{+}$ & 289 & 1.07 \\
\hline & $\mathrm{nC}_{5} \mathrm{nC}_{8}$ & $\mathrm{C}_{17} \mathrm{H}_{34} \mathrm{O}_{4}{ }^{*} \mathrm{H}^{+}$ & 303 & 1.03 \\
\hline & $\mathrm{nC}_{6} \mathrm{nC}_{8}$ & $\mathrm{C}_{18} \mathrm{H}_{36} \mathrm{O}_{4}{ }^{*} \mathrm{H}^{+}$ & 317 & 1.00 \\
\hline & $\mathrm{nC}_{8} \mathrm{nC}_{8}$ & $\mathrm{C}_{20} \mathrm{H}_{40} \mathrm{O}_{4} * \mathrm{H}^{+}$ & 345 & 0.93 \\
\hline \multirow[t]{5}{*}{$\mathrm{iC}_{6} \mathrm{nC}_{\mathrm{x}}$ iso-hexyl* $n$-alkyl dimers } & $\mathrm{nC}_{2} \mathrm{iC}_{6}$ & $\mathrm{C}_{12} \mathrm{H}_{24} \mathrm{O}_{4}{ }^{*} \mathrm{H}^{+}$ & 233 & 1.26 \\
\hline & $\mathrm{nC}_{3} \mathrm{iC}_{6}$ & $\mathrm{C}_{13} \mathrm{H}_{26} \mathrm{O}_{4} * \mathrm{H}^{+}$ & 247 & 1.2 \\
\hline & $\mathrm{nC}_{4} \mathrm{iC}_{6}^{\circ}$ & $\mathrm{C}_{14} \mathrm{H}_{28} \mathrm{O}_{4}{ }^{*} \mathrm{H}^{+}$ & 261 & 1.16 \\
\hline & $\mathrm{nC}_{5} \mathrm{iC}_{6}$ & $\mathrm{C}_{15} \mathrm{H}_{30} \mathrm{O}_{4}{ }^{*} \mathrm{H}^{+}$ & 275 & 1.12 \\
\hline & $\mathrm{nC}_{8} \mathrm{iC}_{6}$ & $\mathrm{C}_{18} \mathrm{H}_{36} \mathrm{O}_{4}{ }^{*} \mathrm{H}^{+}$ & 317 & 1.00 \\
\hline \multirow[t]{6}{*}{$\mathrm{cC}_{6} \mathrm{nC}_{\mathrm{x}}$ cyclohexyl* $n$-alkyl dimers } & $\mathrm{nC}_{2} \mathrm{CC}_{6}$ & $\mathrm{C}_{12} \mathrm{H}_{22} \mathrm{O}_{4}{ }^{*} \mathrm{H}^{+}$ & 231 & 1.28 \\
\hline & $\mathrm{nC}_{3} \mathrm{cC}_{6}$ & $\mathrm{C}_{13} \mathrm{H}_{24} \mathrm{O}_{4}{ }^{*} \mathrm{H}^{+}$ & 245 & 1.22 \\
\hline & $\mathrm{nC}_{4} \mathrm{cC}_{6}$ & $\mathrm{C}_{14} \mathrm{H}_{26} \mathrm{O}_{4}{ }^{*} \mathrm{H}^{+}$ & 259 & 1.18 \\
\hline & $\mathrm{nC}_{5} \mathrm{cC}_{6}$ & $\mathrm{C}_{15} \mathrm{H}_{28} \mathrm{O}_{4}{ }^{*} \mathrm{H}^{+}$ & 273 & 1.13 \\
\hline & $\mathrm{nC}_{6 \mathrm{c}} \mathrm{C}_{6}$ & $\mathrm{C}_{16} \mathrm{H}_{30} \mathrm{O}_{4}{ }^{*} \mathrm{H}^{+}$ & 287 & 1.09 \\
\hline & $\mathrm{nC}_{8} \mathrm{CC}_{6}$ & $\mathrm{C}_{18} \mathrm{H}_{32} \mathrm{O}_{4}{ }^{*} \mathrm{H}^{+}$ & 315 & 1.01 \\
\hline \multirow[t]{5}{*}{$\mathrm{pC}_{6} \mathrm{nC}_{\mathrm{x}}$ phenyl* $n$-alkyl dimers } & $\mathrm{nC}_{2} \mathrm{pC}_{6}$ & $\mathrm{C}_{12} \mathrm{H}_{16} \mathrm{O}_{4}{ }^{*} \mathrm{H}^{+}$ & 225 & 1.38 \\
\hline & $\mathrm{nC}_{3} \mathrm{pC}_{6}$ & $\mathrm{C}_{14} \mathrm{H}_{18} \mathrm{O}_{4} * \mathrm{H}^{+}$ & 239 & 1.32 \\
\hline & $\mathrm{nC}_{4} \mathrm{pC}_{6}$ & $\mathrm{C}_{14} \mathrm{H}_{20} \mathrm{O}_{4}{ }^{*} \mathrm{H}^{+}$ & 253 & 1.27 \\
\hline & $\mathrm{nC}_{6} \mathrm{pC}_{6}$ & $\mathrm{C}_{16} \mathrm{H}_{24} \mathrm{O}_{4}{ }^{*} \mathrm{H}^{+}$ & 281 & 1.18 \\
\hline & $\mathrm{nC}_{8} \mathrm{pC}_{6}$ & $\mathrm{C}_{18} \mathrm{H}_{28} \mathrm{O}_{4}{ }^{*} \mathrm{H}^{+}$ & 309 & 1.07 \\
\hline
\end{tabular}




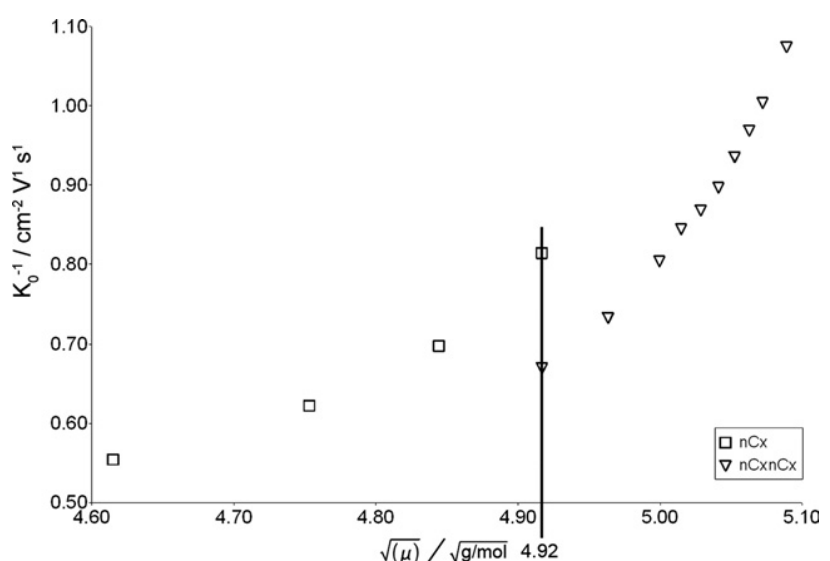

Figure 3. Plot of $1 / K_{0}$ versus $V \mu$ for homologous series of $n$-alkyl monomers and dimers.

operating at above $100{ }^{\circ} \mathrm{C}$. Our investigation was conducted at room temperature $\left(22^{\circ} \mathrm{C}\right)$, which explains the absence of fragmentation. Table 1 shows measured reduced mobility data for all protonated monomers and proton bound dimers analyzed in this study.

The mobility of an ion in a weak electrical field can be described by eq 2 [21].

$$
K=\frac{3 e z \sqrt{2 \pi}\left(1+\alpha_{c}\right)}{16 N \sqrt{\mu k T_{e f f}} \Omega_{D}}
$$

where $\mathrm{K}\left(\mathrm{cm}^{2} \mathrm{~V}^{-1} \mathrm{~s}^{-1}\right)$ is the reduced mobility, e (C) is the charge of an electron, $\mathrm{z}$ is the number of charges, $\mathrm{N}$ $\left(2.6868^{*} 10^{25}\right.$ molecules $\left./ \mathrm{m}^{3}\right)$ is the number density of the drift gas at standard conditions, $\mathrm{k}$ is Boltzmann's constant $\left(1.38,066^{*} 10^{-23} \mathrm{~J} / \mathrm{K}\right), \mu(\mathrm{g})$ is the reduced mass of the ion-neutral pair, $\alpha_{\mathrm{c}}$ is a correction factor less than 0.02 for molecules with a larger mass than the drift gas, $\mathrm{T}_{\text {eff }}(\mathrm{K})$ is the effective ion temperature and $\Omega_{\mathrm{D}}\left(\AA^{2}\right)$ is the collision cross section, which describes the size and shape of the molecule. Since the gas density (pressure), temperature, and charge number is constant, eq 2 can be rewritten as eq 3 .

$$
\frac{1}{K}=\frac{1}{C} \cdot \sqrt{\mu} \cdot \Omega_{D}
$$

Equation 3 shows that the reciprocal mobility $(1 / K)$ is proportional to the product of the collision cross section $(\Omega)$ and the square root of the reduced mass $(\sqrt{\mu})$. For a series of monomers or dimers with increasing chain length of the alkyl chain, a plot of the reciprocal reduced mobility $\left(1 / K_{0}\right)$ against $\sqrt{\mu}$ should give an upward bent curve reflecting the increasing collision cross section with mass. This expected behavior is clearly seen from Figure 3.

The most interesting part of Figure 3 is observed at $\sqrt{\mu}$ equals 4.92 , where the two curves overlap. It is quite clear that for a monomer and a dimer with the same reduced mass, the monomer has a lower reduced mobility and therefore a larger collision cross section than that of the dimer. It has previously been shown that the motion of ions in nitrogen at $200{ }^{\circ} \mathrm{C}$, where cluster formation is minimal [22], can be described by the rigid sphere model [23]. Our experiments were performed at ambient temperature, where the mobility is expected to be influenced by cluster formation, especially with the water ubiquitously present. At ambient temperature, cluster formation with water molecules might be part of the explanation for the lower reduced mobility of monomers compared with dimers with the same mass because the charge on the monomer is much more exposed to the surrounding gas than that of the dimer. Another explanation or contribution to the smaller reduced mobility of the monomer might be that the monomer has a longer $n$-alkyl chain than the dimer, an $n$-alkyl chain that dangles around and creates a larger rigid sphere. It has been shown previously that sticks tend to have larger cross section than balls of same mass [24].

In mixtures of acetate esters, dimers are expected to be formed between all the different esters. To investigate whether structurally different dimers with the same mass can be separated, we recorded the IMS-MS spectrum of a mixture containing ethyl acetate, butyl acetate, hexyl acetate, and octyl acetate. The spectrum is shown in Figure 4, where $m / z 177\left(\mathrm{nC}_{2} \mathrm{nC}_{2}\right), m / z 205$ $\left(\mathrm{nC}_{2} \mathrm{nC}_{4}\right), \quad m / z 233 \quad\left(\mathrm{nC}_{4} \mathrm{nC}_{4}\right.$ and $\left.\mathrm{nC}_{2} \mathrm{nC}_{6}\right), m / z 261$ $\left(\mathrm{nC}_{2} \mathrm{nC}_{8}\right.$ and $\left.\mathrm{nC}_{4} \mathrm{nC}_{6}\right), m / z 289\left(\mathrm{nC}_{4} \mathrm{nC}_{8}\right.$ and $\left.\mathrm{nC}_{6} \mathrm{nC}_{6}\right)$, $\mathrm{m} / \mathrm{z} 317\left(\mathrm{nC}_{6} \mathrm{nC}_{8}\right)$, and $\mathrm{m} / \mathrm{z} 345\left(\mathrm{nC}_{8} \mathrm{nC}_{8}\right)$ was recorded. A total of seven peaks were observed in the spectrum instead of 10, indicating that some of the dimers must have similar reduced mobilities. Using collision activated dissociation in the IMS-MS interface, we could identify the individual acetate components of the dimers and found that dimers of the same mass also had the same reduced mobility. In other words, the

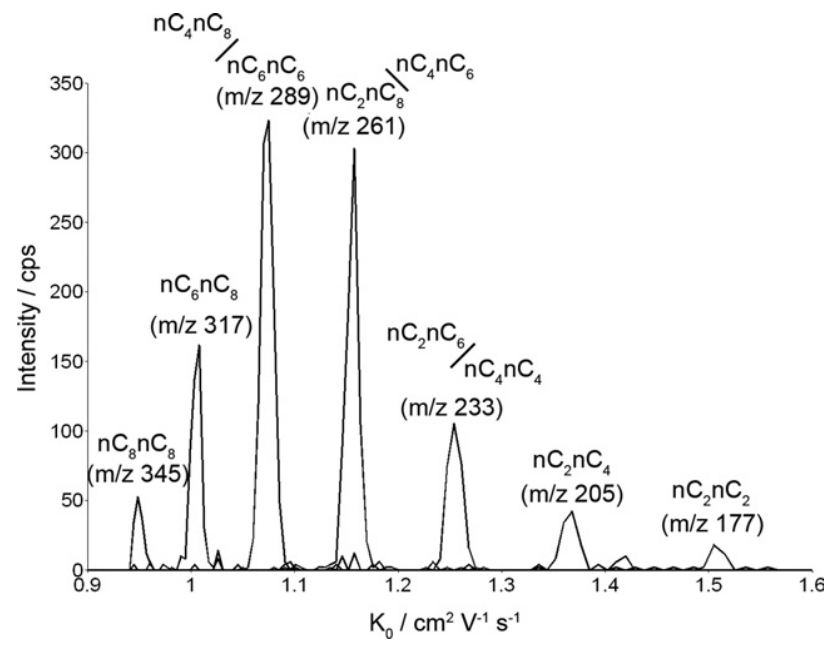

Figure 4. Ion mobility spectrum of a mixture of ethyl, butyl, hexyl, and octyl acetate. Only masses of the mixed dimers were monitored. Number in brackets denotes the monitored mass. 


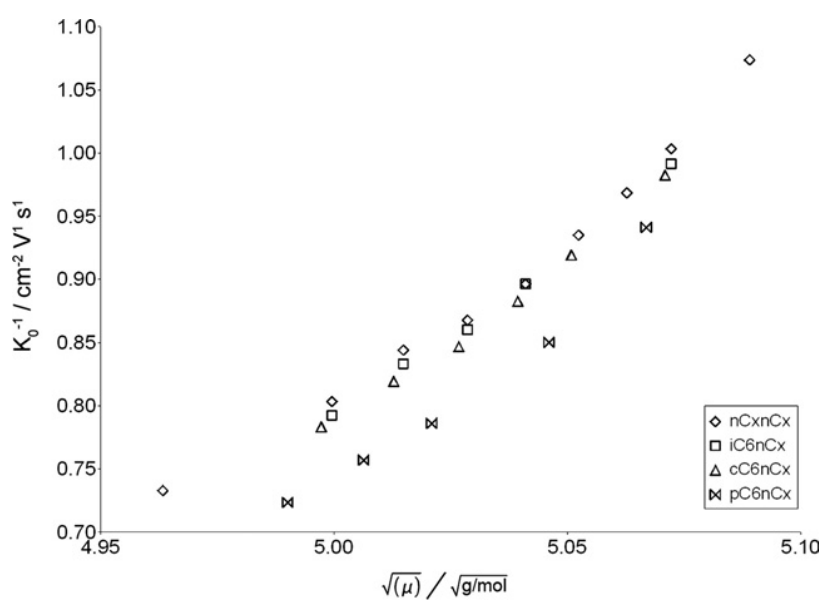

Figure 5. Plot of $1 / K_{0}$ versus $V \mu$ for homologous series of acetate dimers.

$\mathrm{nC}_{4} \mathrm{nC}_{8}$ and $\mathrm{nC}_{6} \mathrm{nC}_{6}$ at $1.07 \mathrm{~cm}^{2} \mathrm{~V}^{-1} \mathrm{~s}^{-1}$, the $\mathrm{nC}_{2} \mathrm{nC}_{8}$ and $\mathrm{nC}_{4} \mathrm{nC}_{6}$ at $1.15 \mathrm{~cm}^{2} \mathrm{~V}^{-1} \mathrm{~s}^{-1}$, and the $\mathrm{nC}_{4} \mathrm{nC}_{4}$ and $\mathrm{nC}_{2} \mathrm{nC}_{6}$ at $1.24 \mathrm{~cm}^{2} \mathrm{~V}^{-1} \mathrm{~s}^{-1}$ have the same reduced mobilities irrespective of the asymmetry in the chain length. The observation that it is the total number of carbons in the $n$-alkyl chains of the dimers that matters might complicate the quantification of molecules with $n$-alkyl substituents, since several ion species might have the same reduced mobility. In particular, this possibility should be considered when reagent gases with $n$-alkyl substituents such as n-nonyl amine [8] or 4-heptanone [9] are used.

To investigate the effect of different substituents (R) in the dimers, we measured the reduced mobilities of series of dimers, where one of the esters in the dimer was either hexyl acetate, iso-hexyl acetate, cyclo-hexyl acetate, or phenyl acetate, and the other ester an $n$-alkyl acetate of varying length. Figure 5 shows the result of a plot of $K_{0}^{-1}$ versus $\sqrt{\mu}$ for the four series of dimers. The figure shows that the reduced mobility of the dimers with a phenyl substituent $\left(\mathrm{pC}_{6} \mathrm{nC}\right)$ is significantly larger (smallest $\mathrm{K}_{0}{ }^{-1}$ ) than that of dimers with either a cyclo-hexyl $\left(\mathrm{CC}_{6} \mathrm{nC}_{\mathrm{x}}\right.$ ), iso-hexyl $\left(\mathrm{iC}_{6} \mathrm{nC} \mathrm{C}_{\mathrm{x}}\right)$, or a hexyl $\left(6 \mathrm{C}_{6} \mathrm{nC}_{\mathrm{x}}\right)$ substituent. The data also shows a small but consistent reduction in reduced mobility from dimers containing a cyclo-hexyl to an iso-hexyl and further to a $n$-hexyl substituent. These findings for acetate dimers are similar to those found in previous investigations of monomers of amines [25] and ketones $[26,27]$.

\section{Conclusions}

Our investigation has shown that dimer formation between acetates is very common in IMS spectra when the analysis is performed at ambient conditions. All acetates studied created dimers between all acetate species present in a mixture. The acetate dimers were found to have a smaller collision cross section than that of an acetate monomer with the same reduced mass. Of particular interest in connection with identification and quantification of compounds containing $n$-alkyl chains, we found that the reduced mobility of an acetate dimer is determined by the total number of carbons in the two alkyl chains. An asymmetric distribution of carbons on the two acetates had no influence upon the reduced mobility. The reduced mobility of the acetate dimers was found to depend upon the substituents and varied in the order of $n$-alkyl $\leq$ branched alkyl $\leq$ cycloalkyl $<$ aromatic.

\section{Acknowledgments}

The authors greatly appreciate financial support for student exchange between the contributing institutions from Nordforsk and Nordplus. The authors acknowledge support from the Danish Natural Science Research Council grant number 21-04-0547. Further support was obtained from National Technology Agency of Finland, the Academy of Finland, Environics Ltd., Orion Pharma, Paavo Ristola Consulting Engineers Ltd., the National Bureau of Investigation, HERC project urban and rural air pollutionresponse of ecosystem and society (URPO), and the Russian Foundation for Support of Small Innovative Enterprises. The authors also acknowledge the Division of Atmospheric Sciences of University of Helsinki for the pressure data.

\section{References}

1. Eiceman, G. A.; Karpas, Z. Ion Mobility Spectrometr, 2nd ed.; CRC Press: Boca Raton, 2005; p 350.

2. Kanu, A. B.; Hill, H. H. Identity Confirmation of Drugs and Explosives in Ion Mobility Spectrometry Using a Secondary Drift Gas. Talanta 2007, 73, 693-699.

3. Kanu, A. B.; Haigh, P. E.; Hill, H. H. Surface Detection of Chemical Warfare Agent Simulants and Degradation Products. Anal. Chim. Acta 2005, 553, 148-159.

4. Ewing, R. G.; Atkinson, D. A.; Eiceman, G. A.; Ewing, G. J. A Critical Review of Ion Mobility Spectrometry for the Detection of Explosives and Explosive Related Compounds. Talanta 2001, 54, 515-529.

5. Seto, Y.; Kataoka, M.; Tsuge, K.; Ohsawa, I.; Matsushita, K.; Sekiguchi, H.; Itoi, T.; Iura, K.; Sano, Y.; Yamashiro, S. Sensing Technology for Chemical Warfare Agents and Its Evaluation Using Authentic Agents. Sens. Act. B 2005, 108, 193-197.

6. Murray, G. M.; Lawrence, D. S. Hazardous Event Monitoring. In Chemical Weapons Convention Chemicals Analysis-Sample Collection, Preparation, and Analytical Methods, Mesilaakso, M., Ed.; John Wiley and Sons Ltd., Chichester, UK, 2005, pp. 65-88.

7. Eiceman, G. A.; Wang, Y.-F.; Garcia-Gonzalez, L.; Harden, C. S.; Shoff D. B. Enhanced Selectivity in Ion Mobility Spectrometry Analysis of Complex Mixtures by Alternate Reagent Gas Chemistry. Anal. Chim. Acta 1995, 306, 21-33.

8. Karpas, Z.; Chaim, W.; Gdalevsky. R.; Tilman, B.; Lorber, A. Novel Application for Ion Mobility Spectrometry: Diagnosing Vaginal Infections through Measurement of Biogenic Amines. Anal. Chim. Acta 2002 474, 115-123.

9. Gan, T. H.; Corino, G. Selective Detection of Alkanolamine Vapors by Ion Mobility Spectrometry with Ketone Reagent Gases. Anal. Chem. 2000, 72, 807-815.

10. Larson, J. W.; McMahon, T. B. Formation, Thermochemistry, and Relative Stabilities of Proton-Bound Dimers of Oxygen $n$-Donor Bases from Ion Cyclotron Resonance Solvent-Exchange Equilibria Measurements. J. Am. Chem. Soc. 1982, 104, 6255-6261.

11. Evans J.; Nicol G.; Munson, B. Proton Affinities of Saturated Aliphatic Methyl Esters. J. Am. Chem. Soc. Mass Spectrom. 2000, 11, 789-796.

12. Ewing, R. G.; Eiceman, G. A.; Stone, J. A. Proton-Bound Cluster in Ion Mobility Spectrometry. Int. J. Mass Spectrom. 1999, 193, 57-68.

13. Marotta, E.; Paradisi, P. Positive Ion Chemistry of Esters of Carboxylic Acids in Air Plasma at Atmospheric Pressure. J. Mass Spectrom. 2005, 40, 1583-1589.

14. Eiceman, G. A.; Nazarov, E. G.; Stone, J. A. Chemical Standard in Ion Mobility Spectrometry. Anal. Chim. Acta 2003, 493, 185-194.

15. Viitanen, A-K.; Mauriala, T.; Mattila, T.; Adamov, A.; Pedersen, C. S.; Mäkelä, J. M.; Marjamäki, M.; Sysoev, A. A.; Keskinen, J.; Kotiaho, T. Adjusting Mobility Scales of Ion Mobility Spectrometers Using 2,6-DtBP as a Reference Compound. Talanta, in press.

16. Meot-Ner, M.; Sieck, L. W. The Ionic Hydrogen Bond. 1. Sterically Hindered Bonds Solvation and Clustering of Protonated Amines and Pyridines. J. Am. Chem. Soc. 1983, 105, 2956-2961. 
17. Sysoev, A.; Adamov, A.; Viidanoja, J.; Ketola, R. A.; Kostiainen, R.; Kotiaho, T. Development of an Ion Mobility Spectrometer for Use in an Atmospheric Pressure Ionization Ion Mobility Spectrometer/Mass Spectrometer Instrument for Fast Screening Analysis. Rapid Commun. Mass Spectrom. 2004, 18, 3131-3139.

18. Tabrizchi, M.; Khayamian, T.; Taj, N. Design and Optimization of a Corona Discharge Ionization Source for Ion Mobility Spectrometry. Rev. Sci. Inst. 2000, 71, 2321-2328.

19. Bradbury, N. E.; Nielsen, R. A. Absolute Values of the Electron Mobility in Hydrogen. Phys. Rev. 1936, 49, 388-393.

20. Eiceman, G. A.; Shoff, D. B.; Harden, C. S.; Snyder, A. P. Fragmentation of Butyl Acetate Isomers in the Drift Region of an Ion Mobility Spectrometer. Int. J. Mass Spectrom. Ion Processes 1988, 85, 265-275.

21. Mason, E. A. Ion Mobility: Its Role in Plasma Chromatography. In Plasma Chromatography, Carr, T. W. Eds.; Plenum Press: New York, 1984; pp. 43-93.
22. Karpas, Z.; Berant, Z.; Shahal, O. Effect of Temperature on the Mobility of Ions. J. Am. Chem. Soc. 1989, 111, 6015-6018.

23. Steiner, W. E.; English, W. A.; Hill, H. H. Jr. Ion-Neutral Potential Models in Atmospheric Pressure Ion Mobility Time-of-Flight Mass Spectrometry IM(TOF)MS. J. Phys. Chem. A 2006, 110, 1836-1844.

24. Gotts, N. G.; von Helden, G.; Bowers M. T. Carbon Cluster Anions: Structure and Growth from $\mathrm{C}_{5}^{-}$to $\mathrm{C}_{62}^{-}$. Int. J. Mass Spectrom. Ion Processes 1995, 149/150, 217-229.

25. Karpas, Z. Ion Mobility Spectrometry of Aliphatic and Aromatic Amines. Anal. Chem. 1989, 61, 684-689.

26. Karpas, Z. Structure and Mobility in Air of Protonated Ketones. Int. J. Mass Spectrom. Ion Processes 1991, 107, 435-440.

27. Karpas, Z.; Cohen, M. J.; Stimac, R. M.; Wernlund, R. F. On the Effects of Structure and Charge Distribution on the Mobility of Ions. Int. J. Mass Spectrom. Ion Processes 1986, 74, 153-159. 